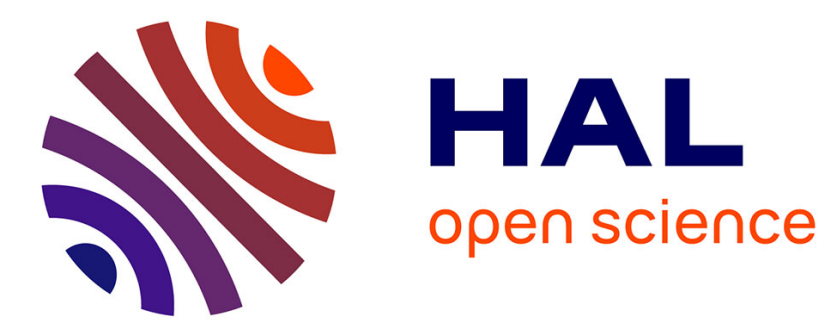

\title{
Bidentate ligation of magnesium by 1,2-dimethoxyethane in the gas phase
}

\author{
S. Soorkia, M. Collier, B. Soep, J.-M. Mestdagh
}

\section{To cite this version:}

S. Soorkia, M. Collier, B. Soep, J.-M. Mestdagh. Bidentate ligation of magnesium by 1,2dimethoxyethane in the gas phase. Journal of Chemical Physics, 2009, 131 (22), pp.224319. 10.1063/1.3270155. hal-00441065

\section{HAL Id: hal-00441065 \\ https://hal.science/hal-00441065}

Submitted on 14 Dec 2009

HAL is a multi-disciplinary open access archive for the deposit and dissemination of scientific research documents, whether they are published or not. The documents may come from teaching and research institutions in France or abroad, or from public or private research centers.
L'archive ouverte pluridisciplinaire HAL, est destinée au dépôt et à la diffusion de documents scientifiques de niveau recherche, publiés ou non, émanant des établissements d'enseignement et de recherche français ou étrangers, des laboratoires publics ou privés. 


\title{
Bidentate ligation of magnesium by 1,2-dimethoxyethane in the gas phase
}

\author{
S. Soorkia, ${ }^{*}$ M. Collier, ${ }^{\dagger}$ B. Soep, and J.-M. Mestdagh ${ }^{\ddagger}$ \\ Laboratoire Francis Perrin, CNRS-URA 2453, CEA, \\ IRAMIS, Service des Photons Atomes et Molécules, \\ F-91191 Gif-sur-Yvette Cedex, France
}

(Dated: November 6, 2009)

\begin{abstract}
The 1:1 Mg $\cdots$ 1,2-dimethoxyethane (Mg-DXE) complexes are studied experimentally and theoretically. They are generated by a laser ablation source in a supersonic expansion. They are studied spectroscopically by Resonance Two-Photon Ionization (R2PI). DFT/B3LYP and ab initio calculations using the MOLPRO quantum chemistry package are performed to document their ground and excited states in a series of geometry ranging from monodentate to bidentate ligation of $\mathrm{Mg}$ by the $\mathrm{O}$ atoms of DXE. An absorption band is observed in the $27800-30500 \mathrm{~cm}^{-1}$ range, which, thanks to the calculations, is attributed to the bidentate complex. The structure of the band is discussed in terms of the excitation of electronic states of the complex correlating adiabatically to the $3 \mathrm{~s} 3 \mathrm{p}^{1} \mathrm{P}$ and $3 \mathrm{~s} 4 \mathrm{~s}^{1} \mathrm{~S}$ states of $\mathrm{Mg}$ at large separation between $\mathrm{Mg}$ and DXE.
\end{abstract}

\footnotetext{
*Present address: Departments of Chemistry and Physics and Lawrence Berkeley National Laboratory, University of California, Berkeley, CA 94720, USA

${ }^{\dagger}$ Present address: Department of Chemistry, National University of Ireland, Maynooth, Maynooth, Co. Kildare, Ireland

${ }^{\ddagger}$ Electronic address: jean-michel.mestdagh@cea.fr
} 


\section{INTRODUCTION}

Crown ethers are important compounds in coordination chemistry for their ability to bind specific metal cations. Their cyclic structure formed by the association of $n$ $-\mathrm{CH}_{2}-\mathrm{CH}_{2}-\mathrm{O}-$ units puts the $n$ oxygen atoms in proper position to bind a metal cation, which is maintained at the centre of the crown. ${ }^{1}$ This corresponds to a polydentate ligation since the metal ion is bound to several anchoring sites of the ligand molecule. A simpler variant of polydentate interaction is found with 1,2-dimethoxyethane (DXE), $\mathrm{CH}_{3}-\mathrm{O}-\mathrm{CH}_{2}-\mathrm{CH}_{2}-\mathrm{O}-\mathrm{CH}_{3}$, which also contains the $-\mathrm{CH}_{2}-\mathrm{CH}_{2}-\mathrm{O}-$ repeating unit (note that the name 1,2-dimethoxyethane is quite often shortened as DME. We nevertheless prefer DXE since it makes no confusion with dimethyl ether). DXE is less rigid than the closed ring of crown ethers and can exist as various rotamers, one of which has the two $\mathrm{O}$ atoms in position to provide a bidentate interaction with a metal ion. It has the conformation labeled tgt ( $t$ for trans and $g$ for gauche) with respect to the O-C, C-C and C-O bonds (Fig. 1 shows the tgt and ttt rotamers and the bond axes, which define the trans and gauche isomerizations). DXE is often used as a benchmark for studying polydentate ligation of ions. ${ }^{2,3}$ Its less pronounced rigidity will appear as an advantage in the present work, which deals with the ligation of neutral metal atoms.

\section{FIGURE 1}

Gas phase studies allow one to form and to study spectroscopically, molecular assemblies, which are free of external perturbations. The purpose then, is to investigate intrinsic properties of these assemblies very directly, and to perform extensive comparisons with theoretical approaches. This is exemplified for DXE-alkali ion ${ }^{2-5}$ and DXE-transition metal ion ${ }^{6,7}$ complexes. A refined analysis of the $\mathrm{M}^{+}-\mathrm{O}$ bonds in the DXE-alkali ion complexes showed that they are non-covalent and determined by electrostatic charge-dipole, polarization and partial charge transfer interactions. The charge transfer is significant for the light alkali ions, $\mathrm{Li}^{+}$and $\mathrm{Na}^{+}$, with a transfer of $0.3 \mathrm{e}^{-}$and $0.1 \mathrm{e}^{-}$, respectively. ${ }^{2,3} \mathrm{The}$ strength of the bidentate interaction of the alkali ion with the two $\mathrm{O}$ atoms of DXE reduces the O-C-C-O dihedral angle from $73.8^{\circ}$ in the $t g t$ rotamer of free DXE down to $47.6^{\circ}$ in the 
$\mathrm{Li}^{+}$(DXE) complex (note that these values depend on the level of the calculation by a few degrees). The effect of reducing the dihedral angle is smaller for the larger cations, in line with the larger $\mathrm{M}^{+}-\mathrm{O}$ bond length when $\mathrm{M}^{+}$goes along the $\mathrm{Li}^{+} \rightarrow \mathrm{Cs}^{+}$sequence. ${ }^{3}$

Much less attention has been given to neutral systems although the M-DXE interaction is quite important from a fundamental point of view. As opposed to metal ions, neutral metal atoms do not exhibit strong bonds with DXE in the ground state. There, the interaction reflects a subtle balance between several contributions, none of which is dominant, in contrast with the situation encountered above with the charge-dipole interaction in $\mathrm{M}^{+}$- DXE. A work by Yeh and Su reports the formation of the $\mathrm{Na}-\mathrm{DXE}$ complex in a flow generator and its photoionization study. The experimental work is complemented by MP2 $a b$ initio and density functional calculations. ${ }^{8}$ It was found that the most stable conformer of the $\mathrm{Na}-\mathrm{DXE}$ complex has a cyclic structure, i.e. Na has a bidentate ligation with DXE. Yang and coworkers also investigated such systems in a work where Li, Na - DXE complexes were produced by the laser vaporization/supersonic beam technique and studied experimentally by ZEKE spectroscopy. ${ }^{9}$ Again, DFT and MP2 calculations complemented the experimental work. The ZEKE spectroscopy was unsuccessful on the $\mathrm{Na}-\mathrm{DXE}$ complex and only adiabatic ionization could be documented, in qualitative agreement to those reported. ${ }^{8}$ In contrast, the ZEKE spectroscopy of the Li - DXE complex yields information on the vibrational modes of the ground state ionized complex, which were fully assigned. Finally, the calculation on the Li - DXE complex showed that the bidentate ligation affects essentially the O-C-C-O dihedral angle of DXE, which is reduced to $49.0^{\circ}$, a value, which is comparable to that encountered above in the ionized complex $\mathrm{Li}^{+}(\mathrm{DXE}){ }^{9}$

The ligation of neutral alkaline earth atoms by DXE offers a further degree of complexity in the ligation mechanism, by the presence of two valence electrons in the atom. In particular the ligation might behave differently whether the alkaline earth atom is in the ground state or electronically excited, because the ground state has a closed shell structure, whereas it is not the case in electronically excited states.

The present work is a first attempt to address this question by documenting the $\mathrm{Mg}$ - DXE complex, in a combined experimental and theoretical approach where the 
ground and the first electronically excited states of the complex are investigated. A motivation is to examine how the ligation of $\mathrm{Mg}$ in various electronic states affects the flexible O-C-C-O dihedral angle of the DXE molecule. The experimental work is performed using the laser vaporization/supersonic beam technique combined with the Resonance Two-Photon Ionization technique. It provides spectroscopic information on the $\mathrm{Mg}-\mathrm{DXE}$ complex. The theoretical work associates B3LYP $/ 6-311++\mathrm{G}^{* *}$ calculations of various $\mathrm{Mg}-\mathrm{DXE}$ geometries in the ground state, ranging from the $t g t$ to the $t t t$ rotamers, with an ab initio approach providing vertical excitation energies at these geometries. This enables to explore the effect of ligation on the magnesium spectroscopy when the ligation switches from bidentate to monodentate. In the latter calculation, the electronic problem is treated by the Internally Contracted Multi-Reference Configuration Interaction method (IC-MRCI) using the pseudo potential approach to reduce the electron problem to that of the valence electrons.

\section{EXPERIMENTAL AND COMPUTATIONAL TECHNIQUES}

\section{A. Experimental}

The experimental apparatus combines a laser ablation system, nanosecond ionization lasers and a linear time-of-flight mass spectrometer (TOF-MS). Briefly, magnesium atoms are evaporated by the laser ablation within the beam source where they are mixed with ligand molecules. The supersonic expansion, which follows, generates the desired $\mathrm{Mg}-\mathrm{DXE}$ complexes among other species. All of them are carried in the beam after collimation. They are ionized using the lasers and the resulting ions are mass analyzed using TOF-MS. More extensive details are given now concerning the various components of the apparatus and the operating procedure.

FIGURE 2 


\section{Beam source}

Cold clusters are generated using the laser evaporation source schemed in Fig. 2. It is composed of a piezoelectric pulsed valve, a nozzle of $0.5 \mathrm{~mm}$ diameter followed by a channel, $1 \mathrm{~mm}$ in diameter. A rotating rod of magnesium $(6 \mathrm{~mm}$ in diameter, $80 \mathrm{~mm}$ long) is ablated by the $532 \mathrm{~nm}$ doubled output of a Nd-YAG laser, in the configuration of Smalley. ${ }^{10}$ A mixture of $1 \%$ DXE in helium is premixed with $10 \%$ argon in a cylinder. It is passed through the nozzle and entrains the $\mathrm{Mg}$ vapor created by the laser ablation in a $10 \mathrm{~mm}$ long channel. The beam is free to expand at the tip of the channel. It produces cold Mg - DXE complexes, but as usual in laser evaporation sources, several other species are present in the beam, including oxides coming from an oxygen pollution of the rod and various types of mixed clusters. The operating conditions are carefully adjusted to optimize the formation of the Mg-DXE complex (see Sec. III A). The pressure in the $10 \mathrm{~mm}$ channel turns out to be an important parameter with this respect. It is controlled by changing the backing pressure of the gas line feeding the pulsed valve and by adjusting the duration of the valve opening. The molecular beam is collimated by a $2 \mathrm{~mm}$ skimmer before entering the chamber where the spectroscopic studies are performed.

\section{Ionization lasers}

A pulsed tuneable dye laser (LambdaPhysik LPD 3000) is pumped by the $532 \mathrm{~nm}$ output of a nanosecond Nd-YAG laser. It is used for the Resonance Two-Photon Ionization (R2PI) study of the complexes. The species present in the molecular beam are characterized by single photon ionization in the range $207-240 \mathrm{~nm}(6.05-5.2 \mathrm{eV})$ by frequency doubling a dye laser delivering tunable light between 414 and $480 \mathrm{~nm}$. An excimer laser (GAM Laser EX5) operating at $157 \mathrm{~nm}$ is used also to ionize these species with a photon energy close to $8 \mathrm{eV}$.

\section{Clocking}

The time delays between the pulsed components of the beam source, lasers and detection tools represent essential parameters to control. This is achieved via a digital delay generator 
controlled by a quartz resonator (designed and build at Laboratoire de PhotoPhysique Moléculaire - LPPM - Université Paris Sud). The time sequence is the following: i) the two Nd-YAG lasers are charged at first. Then, ii), the ablation laser is fired. This defines the time origin $t_{0}$. iii), the pulsed valve is opened at time $t_{1}$. The time delay $t_{1}-t_{0}$ is varied by $1 \mu s$ steps. It is adjusted to ablate magnesium within the leading edge of the gas pulse. The tuning range of $t_{1}-t_{0}$ where complexes are observed is limited to $10 \mu s$. Finally, iv), the ionization laser is fired at a time $t_{2}$ when the complexes arrive in the observation zone. The $\mathrm{t}_{2}-\mathrm{t}_{0}$ time delay is also controlled by $1 \mu \mathrm{s}$ steps.

\section{B. Computational}

Two kinds of calculations are performed. First, a series of geometries of the Mg-DXE complex is generated using the GAUSSIAN 98 package. ${ }^{11}$ It samples the O-C-C-O dihedral angle $\theta$ of DXE between $-180^{\circ}$ and $180^{\circ}$, hence exploring geometrical conformation where the DXE molecule switches between the tgt and the $t t t$ rotamers. Second, vertical excitation energies to the first four excited singlet states of the complex are calculated, at each geometries, using the MOLPRO quantum chemistry package. ${ }^{12}$ A limited exploration of the first four triplet states is also performed.

The GAUSSIAN calculations are performed according to the density functional (DFT) Becke 3-parameter Lee, Yang and Parr (B3LYP) hybrid method in an all-electron treatment, which uses the $6-311++\mathrm{G}^{* *}$ basis set. The modredundant option is used to scan the O-C-C-O dihedral angle $\theta$ of DXE between $-180^{\circ}$ and $180^{\circ}$ by $10^{\circ}$ steps, while optimizing all the other coordinates.

The MOLPRO calculations are aimed at providing accurate excitation energies of the complex in an energy range, which overlaps the $27800-30500 \mathrm{~cm}^{-1}$ range, where an absorption bands is found experimentally. This corresponds to documenting the singlet states of $\mathrm{Mg}$ - DXE, which correlate adiabatically to the $3 \mathrm{~s} 3 \mathrm{p}{ }^{1} \mathrm{P}$ and $3 \mathrm{~s} 4 \mathrm{~s}^{1} \mathrm{~S}$ states of $\mathrm{Mg}$ at large separation between $\mathrm{Mg}$ and DXE. The technique successfully applied $\mathrm{in}^{14}$ to describe the $\mathrm{MgH}$ molecule, is used again. Accordingly, the core electrons of $\mathrm{Mg}$ are described by 
a $\left[\mathrm{Mg}^{2+}\right]$ effective core potential (ECP), complemented by a core-polarization potential (CPP). The parameters defining the ECP and the CPP are given in, ${ }^{14}$ as the uncontracted [10s,11p,9d] Gaussian basis set, which describes the valence electrons of Mg. These choices provide a reliable prediction of the magnesium energy levels, up to the $3 \mathrm{~s} 3 \mathrm{~d}^{1} \mathrm{D}$ state at $46403 \mathrm{~cm}^{-1}$, as discussed. ${ }^{14}$ In particular, the prediction is within $340 \mathrm{~cm}^{-1}$ for the $3 \mathrm{~s} 3 \mathrm{p}^{1} \mathrm{P}$ and $3 \mathrm{~s} 4 \mathrm{~s}{ }^{1} \mathrm{~S}$ states and the ionization energy, which are relevant here (see Tab. I). Triplet states, which are relevant for the discussion below are also reported in the table. The lowest triplet energy is very satisfactory and differs by only $219 \mathrm{~cm}^{-1}$ from the experiment, whereas the upper state is predicted within $657 \mathrm{~cm}^{-1}$, only.

The core electrons of the oxygen $\left(\left[\mathrm{O}^{6+}\right]\right)$ and carbon $\left(\left[\mathrm{C}^{4+}\right]\right)$ atoms in DXE are also described by effective core potentials. Those of Ref. ${ }^{15}$ are used together with the corresponding Gaussian basis set for the valence electrons. Finally the electrons of the $\mathrm{H}$ atoms in DXE are described by the cc-pVDZ basis set. ${ }^{16}$

The electronic problem is treated in the MOLPRO calculations with the same spirit as in our former calculations on the $\mathrm{Ca}-\mathrm{CH}_{3} \mathrm{~F}$ complex. ${ }^{17}$ A RHF calculation of the $\mathrm{Mg}^{+}-\mathrm{DXE}$ ion is performed first. A state-averaged MCSCF calculation of the neutral Mg - DXE complex follows, which reads the orbitals from the RHF calculation. The average includes the 5 lowest singlet states $\left(\mathrm{S}_{0}\right.$ to $\left.\mathrm{S}_{4}\right)$. They correlate adiabatically to the $3 \mathrm{~s}^{2}{ }^{1} \mathrm{~S}, 3 \mathrm{~s} 3 \mathrm{p}{ }^{1} \mathrm{P}$, and $3 \mathrm{~s} 4 \mathrm{~s}{ }^{1} \mathrm{~S}$ states of magnesium at large $\mathrm{Mg}-\mathrm{DXE}$ separation. The active space of the MCSCF calculation consists of two electrons in 10 orbitals (asymptotically correlating to the $3 \mathrm{~s}, 3 \mathrm{p}, 4 \mathrm{~s}$ and $3 \mathrm{~d}$ orbitals of $\mathrm{Mg}$ ). This provides the reference states of the Internally Contracted Multi Reference Configuration Interaction (IC-MRCI) calculation, ${ }^{18}$ which provides the results presented below. Due to the state averaging, which includes states of fairly large energy, the ground state is not extremely accurate in this calculation. We preferred a separate MCSCF+IC-MRCI calculation, which includes this sole state. Then, a reduced active space of 2 electrons in 5 orbitals is sufficient.

TABLE I 


\section{RESULTS}

\section{A. Characterization of the beam}

Mg-DXE complexes are easily formed and detected by a one-photon ionization at $212 \mathrm{~nm}$. The mass spectrum shown in Fig. 3 is typical of those observed under soft expansion conditions, which are achieved by complying with three factors: i) minimum opening time of the pulsed valve; $i$ ) lowest possible backing pressure in the foreline and $i i i$ ) minimum concentration of DXE in the backing gas. This ensures that the 1:1 Mg - DXE complex is the dominant species among Mg clusters as observed in Fig. 3.

FIGURE 3

\section{B. Resonant Two-Photon Ionization (R2PI)}

The R2PI study of the 1:1 Mg - DXE complex is performed with the laser tuned in the 25000-33000 $\mathrm{cm}^{-1}$ energy range (3.1-4.1 eV). The complex is found to have absorption bands within this range, between 27800 and $30500 \mathrm{~cm}^{-1}$, enabling the R2PI scheme. A first photon is absorbed by the complex to an electronic state, which is sufficiently long lived to be ionized by a second photon of same wavelength. The large ion signal observed at $\mathrm{m} / \mathrm{z}=114$ corresponds to the $1: 1 \mathrm{Mg}^{+}-$DXE ion with no indication of fragmentation to smaller masses or broadening of the mass peak.

The $\mathrm{Mg}^{+}-$DXE ion signal is obtained by integrating the mass peak at the relevant mass at the output of the TOF-MS. It is shown in Fig. 4 as a function of the frequency of the R2PI laser. The three curves in the figure are recorded when tuning the TOF-MS to 114, 115 and 116 amu, which correspond to the mass of the complex when formed from

the ${ }^{24,25,26} \mathrm{Mg}$ isotopes, respectively. The three spectra have the same shape. They have a weakly structured wing between $27800 \mathrm{~cm}^{-1}$ and $28380 \mathrm{~cm}^{-1}$, which is followed by strong structures. The latter belong apparently to a long vibrational progression, but although 
the spacing of the structures appears regular, their intensity is very irregular. A shoulder of weaker intensity appears above $29500 \mathrm{~cm}^{-1}$. It is weakly and irregularly structured.

\section{FIGURE 4}

The vibrational progression displayed in Fig. 4 does not seem to be shifted, within the experimental uncertainties, when switching from an isotope of magnesium to the other. Given the width of the vibrational bands, 40 to $60 \mathrm{~cm}^{-1}$, if existing, the isotope shifts must be smaller than 10 to $20 \mathrm{~cm}^{-1}$. This small value is an indication that $\mathrm{Mg}$ is not directly involved in the vibrational mode corresponding to the progression observed in Fig. 4 as it would be the case, for instance, in the Mg-DXE stretching mode. Fig. 5 shows the expected isotope shift for this mode, assuming a vibrational frequency $\omega_{\mathrm{e}}=110 \mathrm{~cm}^{-1}$, which corresponds approximately to the separation between the large amplitude structures observed in Fig. 4. This figure is built from the expression below, which describes the isotopic shift as a mass effect in the anharmonic oscillator approximation: ${ }^{19}$

$$
\omega_{\mathrm{e}}^{\mathrm{i}^{\prime}}-\omega_{\mathrm{e}}^{\mathrm{i}}=(\rho-1) \omega_{e}^{i}
$$

with

$$
\rho=\sqrt{\frac{\mu^{i}}{\mu^{i^{\prime}}}}
$$

In these expressions, $i$ and $i$ ' distinguish the two isotopes, $\mu^{\mathrm{i}, \mathrm{i}^{\prime}}$ being their reduced masses and $\omega_{\mathrm{e}}^{\mathrm{i}, \mathrm{i}^{\prime}}$ the corresponding vibrational frequencies. The predicted effect amounts to more than $20 \mathrm{~cm}^{-1}$ when the vibrational quantum number $\mathrm{v}$ is larger than $\mathrm{v}=6$. Since the v-dependent isotopic shift of the experimental observation falls below this value, magnesium is presumably not involved directly in the Mg-DXE deformation mode, which produces the large amplitude progression observed in Fig. 4. A deformation mode, which is not strongly coupled to the movement of $\mathrm{Mg}$, is for instance the torsion of the DXE moiety. 


\section{FIGURE 5}

\section{Calculations}

Fig. 6 shows a cut of the ground state energy surface $\mathrm{S}_{0}$ of the Mg-DXE complex along the O-C-C-O dihedral angle. The full curve is provided by the DFT/B3LYP calculation and the dashed curve by the MCSCF+IC-MRCI calculation. As seen in Sec II B, the potential energy of the complex is optimized in the DFT/B3LYP calculation for all the coordinates at a fixed dihedral angle, $\theta$. The same calculation is then repeated at different dihedral angles such that $-180^{\circ}<\theta<180^{\circ}$ in order to explore the ligation of $\mathrm{Mg}$ by DXE. Two equivalent absolute energy minima are found along the DFT/B3LYP curve in the figure when the $\mathrm{O}-\mathrm{C}-\mathrm{C}-\mathrm{O}$ dihedral angle is equal to $\pm 60^{\circ}$. They correspond to the DXE moiety in the gauche configuration with respect to the $\mathrm{C}-\mathrm{C}$ central axis. Two equivalent secondary minima are also observed with the dihedral angle equal to $\pm 180^{\circ}$. Their energy is $110 \mathrm{~cm}^{-1}$ higher than that of the absolute minima. The height of barrier separating the absolute and secondary minima is $880 \mathrm{~cm}^{-1}$, whereas that between the two equivalent absolute minima at $\pm 60^{\circ}$ is $1810 \mathrm{~cm}^{-1}$. The DFT/B3LYP curve (full curve) is compared in the figure to that provided by the MCSCF + IC-MRCI calculation (dashed curve). Both are in qualitative agreement. Nevertheless, the equivalent absolute minima in the latter calculation are observed with the O-C-C-O dihedral angle equal to $\pm 48^{\circ}$, the energy of the secondary minima is $366 \mathrm{~cm}^{-1}$ and the barrier heights of 880 and $1810 \mathrm{~cm}^{-1}$ in the DFT/B3LYP calculation are changed to 1552 and $1035 \mathrm{~cm}^{-1}$, respectively.

\section{FIGURE 6}

The Mg-DXE binding energy, uncorrected for the Basis Set Superposition Error (BSSE), can be estimated by the energy difference between the MCSCF+IC-MRCI calculation for the ground state complex at the absolute minimum and the same calculation 
when $\mathrm{Mg}$ is put at a very large distance $(100 \AA)$. The estimated binding energy is $1580 \mathrm{~cm}^{-1}$.

Fig. 7 shows a cut of the ground state $S_{0}$ and of the four lowest singlet excited potential energy surfaces $\mathrm{S}_{1}$ to $\mathrm{S}_{4}$ of the Mg-DXE complex provided by the MCSCF+IC-MRCI calculation, as a function of the $\mathrm{O}-\mathrm{C}-\mathrm{C}-\mathrm{O}$ dihedral angle. The upper curve of the figure is the RHF energy of the ground state $\mathrm{Mg}^{+}$-DXE ion. The four excited curves and the ionic curve document the vertical excitation and the vertical ionization energy of the complex from each point of the ground state curve. Qualitatively, these four states show a similar behavior, yet significantly different from that of the ground state. In particular, the barrier between the equivalent absolute minima at $\pm 48^{\circ}$ in the ground state does not exist in the excited states, nor in the ion. Instead, a flat minimum extending between $-40^{\circ}$ and $+40^{\circ}$ is observed along each curve.

\section{FIGURE 7}

The experimental R2PI signal shown in Fig. 4 is reproduced in Fig. 7, assuming that the experimental spectrum corresponds to a vertical excitation from either the absolute or the secondary minimum of the ground state curve. The experimental spectrum overlaps the potential energy curves, when an excitation from the absolute minimum at $\pm 48^{\circ}$ is assumed, whereas is significantly below the potential energy curves with the other assumption.

We already mentioned a striking observation in Fig. 7: the four excited curves and the ionic curve of the Mg-DXE system have a similar behavior as the O-C-C-O dihedral angle $\theta$ of DXE is varied. This finds an easy interpretation in Fig. 8. The latter displays the first excited orbital of the Mg-DXE system provided by the state averaged MCSCF calculation. The large size of the excited orbital, compared to the size of the DXE molecule, lets the underlying $\mathrm{Mg}^{+}$ion almost free to interact with the DXE molecule, with little screening by the excited orbital. The dominant configuration corresponding to the first excited state of the Mg-DXE system has an electron in this orbital, hence creating the condition for a similar variation of the interaction energy of both this excited state of $\mathrm{Mg}-\mathrm{DXE}$ and the ground state of $\mathrm{Mg}^{+}-$DXE upon torsion of the DXE moiety. Such an interpretation is also 
valid for the three other excited states of Mg-DXE, which appear in Fig. 7. The size of the excited orbitals associated with these states is indeed comparable or larger than that of the first excited orbital shown in Fig. 8. In particular, the DXE moiety is very much embedded into the orbital of either dominant $4 \mathrm{~s}$ or $3 \mathrm{p}$ character, when the $3 \mathrm{p}$ orbital is perpendicular to the $\mathrm{C}-\mathrm{C}$ bond of the molecule.

\section{FIGURE 8}

The other salient feature in Fig. 7 is the very different behavior of the ground state on the one hand and the excited states on the other, upon the torsion motion of the DXE moiety. The ground state behavior is a consequence of a compensation between a stronger attraction between $\mathrm{Mg}$ and DXE when the DXE torsion makes the two oxygen atoms facing $\mathrm{Mg}$ and a repulsive interaction between the two oxygen atoms. In contrast in the excited states, the attraction between $\mathrm{Mg}^{+}$ion underneath the excited orbital and the oxygen atoms overwhelms the repulsion between the two $\mathrm{O}$ atoms. Hence, the excited potential is essentially flat as long as the two $\mathrm{O}$ atoms are in position to interact with the $\mathrm{Mg}^{+}$ion core. Fig. 8 shows that this is still possible when the $\mathrm{O}-\mathrm{C}-\mathrm{C}-\mathrm{O}$ dihedral angle $\theta$ is $60^{\circ}$. Nevertheless, the energy of the excited states increases slightly, due to the destabilization of the ground state, which makes the distance between $\mathrm{Mg}$ and the $\mathrm{O}$ atoms to increase. It switches from 2.41 to $2.79 \AA$ when $\theta$ is changed from $0^{\circ}$ to $60^{\circ}$. At larger values of $\theta$, a single $\mathrm{O}$ atom interacts with the $\mathrm{Mg}^{+}$ion core, reducing substantially the stabilization of the excited states. This effect accounts for the substantial enhancement of the excited state energies when $\theta>60^{\circ}$. This enhancement is even larger because the ground state itself is slightly destabilized and the distance between $\mathrm{Mg}$ and the closest $\mathrm{O}$ atom goes up to $3.47 \AA$ at $\theta=180^{\circ}$. 


\section{DISCUSSION}

\section{A. Conformation of the ground state Mg-DXE complex}

The conformational landscape of DXE is quite complex since numerous rotamers are formed by rotation of the chemical groups forming the DXE molecule about the three axes shown in Fig. 1. The available information, which is both experimental and theoretical has been reviewed recently. ${ }^{21}$ It indicates that the total population of the gauche rotamers with respect to the O-C-C-O torsion, is dominant in the gas phase at $273.15 \mathrm{~K}$ over that of the trans rotamer. The population ratio between the $\mathrm{O}-\mathrm{C}-\mathrm{C}-\mathrm{O}$ gauche and trans rotamers is ranging between 71:29 and 79:21, with the gauche rotamers corresponding to tgt and tgg' essentially and the trans rotamer corresponding to $t t t$ (the gg' notation indicates that the two gauche torsions have opposite orientations). The larger gauche fraction is due to the larger statistical weight of the corresponding rotamers, which inverts the fact that they are slightly less stable than the $t t t$ rotamer $\left(t g t\right.$ is $108 \mathrm{~cm}^{-1}$ less stable than $\left.t t t\right) .{ }^{21}$

The gauche rotamers of DXE have the two $\mathrm{O}$ atoms in proper position for a bidentate ligation of magnesium, whereas the trans rotamer is expected to lead to a monodentate ligation. The Mg-DXE complex is formed in the present work by collision between $\mathrm{Mg}$ and DXE in the supersonic expansion. Given that the DXE molecule has essentially the gauche configuration in the gas phase, we infer that the complex should be of the bidentate type, essentially. This expectation is reinforced by the fact that the bidentate ligation of $\mathrm{Mg}$ is favored energetically over the monodentate ligation. Fig. 6 shows indeed that the well at $180^{\circ}$ ( $t t$ t rotamer), which is associated with the monodentate ligation is higher in energy than the well corresponding to the bidentate ligation. Nevertheless, the tgt and $t t t$ rotamers of free DXE are separated by a barrier of about $900 \mathrm{~cm}^{-1}(0.11 \mathrm{eV}),{ }^{21}$ which is almost not reduced by the ligation (see Fig. 6). This barrier might not be overcome in the molecular beam source when Mg collides the small fraction of $t t t$ DXE molecule, which is present in the gas phase. Hence, a minor fraction of monodentate Mg-DXE complexes may exist in the beam. However, according to the assignment performed in Sec. IV C, this does not seem to be the case. 
The fact that the Mg-DXE complex is easily formed in supersonic expansion is consistent with the fairy large binding energy of $1580 \mathrm{~cm}^{-1}$, which is estimated from the MCSCF+ICMRCI calculation.

\section{B. The $(\mathrm{Mg}-\mathrm{DXE})^{+}$molecular ion}

Sec. III A shows that the Mg-DXE complex can be ionized by $212 \mathrm{~nm}(5.85 \mathrm{eV})$ photons. Given the ionization energy of free magnesium, $7.644 \mathrm{eV},{ }^{13}$ the ionization energy of the complex is lowered by at least $1.8 \mathrm{eV}$ compared to that of free magnesium. The calculation shown in Fig. 7 is consistent with this observation since the ionization energy of the bidentate complex taken along the dotted-dashed line at $48^{\circ}$ is found to be $43082 \mathrm{~cm}^{-1}$ $(5.34 \mathrm{eV})$, corresponding to a stabilization of the $\mathrm{Mg}^{+} \mathrm{DXE}$ ion by $2.32 \mathrm{eV}$ with respect to the dissociation as $\mathrm{Mg}^{+}+$DXE.

The R2PI spectra of Fig. 4 are extending between 27800 and $30500 \mathrm{~cm}^{-1}$ (3.45 to $3.78 \mathrm{eV}$ ). Hence, 6.90 to $7.56 \mathrm{eV}$ are available for the ionization. Since the calculated ionization energy of the complex is $5.34 \mathrm{eV}$, an excess energy of 1.6 to $2.2 \mathrm{eV}$ is available, which is shared between the kinetic energy of the photoelectron and the internal excitation of the molecular ion. This excess energy is not large enough for the ion to dissociate as $\mathrm{Mg}^{+}+$DXE. The fact that no fragment ion is observed in the R2PI experiment, suggests that either no other fragmentation channels is accessible energetically or, if existing, that an activation barrier makes the ion stable.

\section{Electronic excitation of Mg-DXE and excited state dynamics}

Fig. 7 brings the R2PI signal observed experimentally together with the calculated potential energy curves, according to the assumption that the vertical excitation proceeds either from the absolute minimum of the ground state at $\pm 48^{\circ}$ (bidentate ligation of $\mathrm{Mg}$ by the tgt DXE rotamer) or from the secondary minimum at $\pm 180^{\circ}$ (monodentate ligation by the $t t t$ rotamer). 
The experimental signal overlaps the calculated curve when the bidentate solvation is assumed, whereas no overlap is observed in the other case. The discrepancy is then c.a. $4000 \mathrm{~cm}^{-1}$. This large value can hardly be assigned to the accuracy of the calculation. The agreement between experiment and calculation for the $3 \mathrm{~s}^{2}{ }^{1} \mathrm{~S} \rightarrow 3 \mathrm{~s} 3 \mathrm{p}^{1} \mathrm{P} 3 \mathrm{~s}^{2}{ }^{1} \mathrm{~S} \rightarrow 3 \mathrm{~s} 4 \mathrm{~s}^{1} \mathrm{~S}$ transitions of free $\mathrm{Mg}$ is indeed better than $340 \mathrm{~cm}^{-1}$ (see Sec. IIB and Tab. I) and these states correlate adiabatically to the molecular states of the Mg-DXE complex shown in Fig. 7. Hence, we consider that the accuracy on the calculated molecular state is large enough to state from Fig. 7, that the R2PI spectrum observed between 27800 and $30500 \mathrm{~cm}^{-1}$ is due to the Mg-DXE complex with a bidentate ligation of Mg by DXE. The fact that an intense R2PI signal is observed suggests that one or several of the electronic states of Mg-DXE, which can be accessed resonantly from the ground state bidentate complex, are sufficiently long lived to be ionized efficiently. The purpose now is to identify these states.

The Franck-Condon region of excitation of the complex, corresponding to the bidentate ligation of $\mathrm{Mg}$, with the $\mathrm{O}-\mathrm{C}-\mathrm{C}-\mathrm{O}$ dihedral angle equals to $48^{\circ}$, is shown as a dotted-dashed line in Fig. 7. It crosses the excited potential curves at 25492, 27416, 28151 and $29863 \mathrm{~cm}^{-1}$ as listed in Tab. II. The states, which are crossed at the three lowest energies, i.e. $\mathrm{S}_{1}, \mathrm{~S}_{2}$ and $\mathrm{S}_{3}$ correlate adiabatically to $\mathrm{Mg}\left(3 \mathrm{~s} 3 \mathrm{p}^{1} \mathrm{P}\right)$ at infinite separation between $\mathrm{Mg}$ and $\mathrm{DXE}$. The fourth state, $\mathrm{S}_{4}$, correlates adiabatically to $\mathrm{Mg}\left(3 \mathrm{~s} 4 \mathrm{~s}{ }^{1} \mathrm{~S}\right)$. Excitation to this state would be symmetry forbidden in free $\mathrm{Mg}$, but the transition is allowed in the complex because of the presence of DXE, which lowers the symmetry of the system and mixes the 4s orbital with the $3 p$ orbital, which is pointing towards the central C-C bond of DXE. Hence, vertical excitation to each of these levels is possible. They are discussed in the next section as tools to assign the observed features of the R2PI spectrum to the excitation of the Mg-DXE complex to specific molecular energy states.

\section{TABLE II}




\section{Identification of three bright states}

According to the Franck-Condon picture, the R2PI spectrum of the Mg-DXE complex shown in Fig. 7 should feature maxima or shoulders when the photon energy matches a vertical one-photon resonance with excited states of the complex. According to the previous section, such resonances are expected at 25492, 27416, 28151 and $29863 \mathrm{~cm}^{-1}$ from the MCSCF+IC-MRCI calculation, corresponding to the vertical excitation of the $\mathrm{S}_{1}, \mathrm{~S}_{2}, \mathrm{~S}_{3}$ and $\mathrm{S}_{4}$ states of the complex, respectively.

The expected feature of larger energy at $29863 \mathrm{~cm}^{-1}$ falls within the blue shoulder of weak intensity of the absorption spectrum (between 29600 and $30500 \mathrm{~cm}^{-1}$ ) observed in Fig. 7. We thus assign this shoulder to the excitation of the $\mathrm{S}_{4}$ state, which correlates adiabatically to $\mathrm{Mg}\left(3 \mathrm{~s} 4 \mathrm{~s}^{1} \mathrm{~S}\right)$.

The expected features at 27416 and $28151 \mathrm{~cm}^{-1}$, fall within $900 \mathrm{~cm}^{-1}$ of the structured region of the absorption spectrum (between 28300 and $29600 \mathrm{~cm}^{-1}$ ). This suggests that the vertical excitation to $\mathrm{S}_{2}$ and $\mathrm{S}_{3}$, which correlate adiabatically to $\mathrm{Mg}\left(3 \mathrm{~s} 3 \mathrm{p}{ }^{1} \mathrm{P}\right)$, participate to this region of the R2PI spectrum. Moreover, Fig. 7 shows also that the equilibrium geometry of the $\mathrm{S}_{2}$ and $\mathrm{S}_{3}$ states is planar along the O-C-C-O dihedral angle, whereas the vertical excitation from the equilibrium geometry of $S_{0}$ forms these states in a gauche geometry, with the dihedral angle equal to $48^{\circ}$. Hence, a strong excitation of the torsion mode of the DXE moiety is expected by this excitation. This is consistent with the observation made in Sec. III B that the vibrational progression with $\omega_{\mathrm{e}}=110 \mathrm{~cm}^{-1}$ observed in Fig. 4 does not involve the displacement of the $\mathrm{Mg}$ atom, directly. Moreover, the shape of the middle curve correlating adiabatically to $\mathrm{Mg}\left(3 \mathrm{~s} 3 \mathrm{p}^{1} \mathrm{P}\right)$ can be adequately fitted by a parabola, consistent with a harmonic torsion oscillator with $\omega_{\mathrm{e}}=110 \mathrm{~cm}^{-1}$. Nevertheless, the experimental spectrum cannot be fitted satisfactorily by a single progression. This observation is in line with the fact that two different electronic states participate to the R2PI spectrum in this region and perturbs each other. 


\section{E. Identification of a dark state}

The last expected feature in the R2PI spectrum correspond to the vertical excitation of $\mathrm{S}_{1}$, which correlates with $\mathrm{Mg}\left(3 \mathrm{~s} 3 \mathrm{p}^{1} \mathrm{P}\right)$. It is predicted at $25492 \mathrm{~cm}^{-1}$ and falls $2300 \mathrm{~cm}^{-1}$ below the red wing of the R2PI spectrum at $27800 \mathrm{~cm}^{-1}$. The region overlapping $25492 \mathrm{~cm}^{-1}$ was explored experimentally and no R2PI signal was observed. Nevertheless, there is no doubt from the calculation that an energy state exists in this region, and that it is accessible through a strongly allowed transition. The transition dipole moment of the $\mathrm{S}_{1} \leftarrow \mathrm{S}_{0}$ vertical excitation, provided by the MCSCF+IC-MRCI calculation, is indeed 2.23 e $\mathrm{a}_{0}$, almost as large as the strongly allowed $3 \mathrm{~s} 3 \mathrm{p}^{1} \mathrm{P} \leftarrow 3 \mathrm{~s}^{2}{ }^{1} \mathrm{~S}$ of free $\mathrm{Mg}\left(2.33\right.$ e $\left.\mathrm{a}_{0}\right)$.

We thus infer that the excitation to $\mathrm{S}_{1}$ does not lead to an observable R2PI signal because a non-adiabatic energy transfer is at play, which evacuates the electronic energy out of this state in a short time compared to the 3 ns duration of the R2PI laser pulse. A possible interpretation could be a bond rearrangement within the $S_{1}$ surface, or a strong coupling between this surface and $S_{0}$ through a conical intersection. A limited exploration of the $\mathrm{S}_{1}$ surface was performed, which does not support this assumption. An alternative interpretation is a coupling between the $S_{1}$ surface and a triplet surface. Fig. 9 shows a correlation diagram of the first singlet and triplet states of free $\mathrm{Mg}$ with those of the Mg-DXE complex. It is built using the energies given in Tabs. I and II and the binding energy, which has been calculated for the ground state complex $\left(1580 \mathrm{~cm}^{-1}\right)$. This diagram brings the important result that only the $\mathrm{T}_{3}$ state is repulsive toward the $\mathrm{Mg}+\mathrm{DXE}$ dissociation and from Tab. II we know that this state is $259 \mathrm{~cm}^{-1}$ above $\mathrm{S}_{1}$. $\mathrm{S}_{1}$ is thus expected to be strongly coupled to the dissociative $\mathrm{T}_{3}$ state in the excitation region and results in the formation of $\mathrm{Mg}\left(3 \mathrm{~s} 3 \mathrm{p}^{3} \mathrm{P}\right)+$ DXE. The R2PI experiment is performed with a single color, and Fig. 9 shows that a photon exciting the $\mathrm{S}_{1}$ of the complex from $\mathrm{S}_{0}$ does not have enough energy to ionize free $\mathrm{Mg}$ in the $3 \mathrm{~s} 3 \mathrm{p}^{3} \mathrm{P}$ state.

\section{FIGURE 9}

Hence we surmise that $S_{1}$ is a dark state because its lifetime is considerably reduced by 
the coupling with the $\mathrm{T}_{3}$ state, which dissociates as $\mathrm{Mg}\left(3 \mathrm{~s} 3 \mathrm{p}{ }^{3} \mathrm{P}\right)+\mathrm{DXE}$, the $\mathrm{Mg}$ atom, not being detectable with photons of $25492 \mathrm{~cm}^{-1}$.

\section{SUMMARY AND CONCLUSIONS}

The 1:1 Mg ‥ 1,2-dimethoxyethane (Mg-DXE) complex was explored experimentally. It was generated in a laser ablation source and studied spectroscopically by Resonance Two-Photon Ionization (R2PI). The experiment was complemented by calculations, DFT/B3LYP and $a b$ initio, to document the ground state and the four lowest excited electronic states, which correlate adiabatically to the $3 \mathrm{~s} 3 \mathrm{p}^{1} \mathrm{P}$ and $3 \mathrm{~s} 4 \mathrm{~s}^{1} \mathrm{~S}$ states of $\mathrm{Mg}$ at large separation between $\mathrm{Mg}$ and DXE, for a series of geometry ranging from monodentate to bidentate ligation of $\mathrm{Mg}$ by the oxygen atoms of DXE. A complex absorption band is observed in the R2PI spectrum between 27800 and $30500 \mathrm{~cm}^{-1}$. The combined experiments and calculations show that it must be attributed to the bidentate complex, the bond between the metal and DXE being generated by the interaction of the Mg atom with the two oxygen atoms of DXE. The calculation showed that the ground state bidentate complex is $366 \mathrm{~cm}^{-1}$ more stable than the monodentate complex. Moreover, the DXE moiety has a gauche geometrical configuration at the optimum geometry of the ground state complex, also adapted to the bidentate ligation. An exploration of the O-C-C-O dihedral angle of DXE showed that the DXE moiety adopts a planar chair geometrical configuration in the excited states, which is also adapted to a bidentate ligation. Because of the geometry difference between the ground and excited states, a well pronounced progression assigned to the torsion mode along the $\mathrm{C}-\mathrm{C}$ bond dominates the R2PI spectrum. Finally, the quantum calculations suggests that the observed band is actually the superposition of three electronic bands, hence explaining the complex nature of the observed R2PI spectrum.

The present operating conditions did not allow to form $\mathrm{Mg}(\mathrm{DXE})_{2}$ complexes. Nevertheless, their study would be interesting from a fundamental point of view. The geometry of such 4-ligated complexes could be quite far away from planarity as it is the case when an alkali ion is ligated by two DXE molecules. ${ }^{3}$ This situation would offer interesting comparisons with the ligation by suitable crown ethers, which are essentially planar. 


\section{Acknowledgments}

Partial support is acknowledged from the European Community through the PICNIC network (Product Imaging and Correlation: Nonadiabatic Interactions in Chemistry) under contract number HPRN-CT-2002-00183. JMM thanks A. Lasoroski for her help, when running the Gaussian calculations. 
1 J. M. Lehn, Acc. Chem. Res. 11, 49 (1978).

2 D. Ray, D. Feller, M. B. More, E. D. Glendening, and P. B. Armentrout, J. Phys. Chem. 100, $16116(1996)$.

3 S. E. Hill, D. Feller, and E. D. Glendening, J. Phys. Chem. A 102, 3813 (1998).

4 M. B. More, D. Ray, and P. B. Armentrout, J. Phys. Chem. A 101, 831 (1997).

5 M. B. More, D. Ray, and P. B. Armentrout, J. Phys. Chem. A 101, 7007 (1997).

6 S. Le Caer, M. Heninger, J. Lemaire, P. Boissel, P. Maitre, and H. Mestdagh, Chem. Phys. Lett. 385, 273 (2004).

7 S. Le Caer, M. Heninger, P. Pernot, and H. Mestdagh, J. Phys. Chem. A 110, 9654 (2006).

8 T. S. Yeh and T. M. Su, J. Phys. Chem. A 101, 1672 (1997).

9 B. R. Sohnlein, S. G. Li, J. F. Fuller, and D. S. Yang, J. Chem. Phys. 123, 014318 (2005).

10 D. E. Powers, S. G. Hansen, M. E. Geusic, A. C. Puiu, J. B. Hopkins, T. G. Dietz, M. A. Duncan, P. R. R. Langridge-Smith, and R. E. Smalley, J. Phys. Chem. 86, 2556 (1982).

11 M. J. Frisch, G. W. Trucks, H. B. Schlegel, G. E. Scuseria, M. A. Robb, J. R. Cheeseman, V. G. Zakrzewski, J. J. A. Montgomery, R. E. Stratmann, J. C. Burant, et al., Gaussian 98, revision a.11.3 (2002).

12 H.-J. Werner, P. J. Knowles, R. Lindh, F. R. Manby, M. Schütz, P. Celani, T. Korona, G. Rauhut, R. D. Amos, A. Bernhardsson, et al., Molpro, version 2006.1, a package of ab initio programs (2006), see http://www.molpro.net.

13 C. E. Moore, Atomic Energy Levels, Circular 467, Vol I (NBS, US Dept. of Commerce, 1949).

14 J. M. Mestdagh, P. de Pujo, B. Soep, and F. Spiegelman, Chem. Phys. Lett. 471, 22 (2009).

15 A. Bergner, M. Dolg, W. Kuchle, H. Stoll, and H. Preuss, Mol. Phys. 80, 1431 (1993).

16 T. H. Dunning, Jr, J. Chem. Phys. 90, 1007 (1989).

17 J. M. Mestdagh, F. Spiegelman, E. Gloaguen, M. Collier, F. Lepetit, M. A. Gaveau, C. S. Sanz, and B. Soep, J. Phys. Chem. A 110, 7355 (2006).

18 H.-J. Werner and P. J. Knowles, J. Chem. Phys. 89, 5803 (1988), URL http://dx.doi.org/ $10.1063 / 1.455556$.

19 G. Herzberg, Molecular Spectra and Molecular Structure (van Nostrand company, Inc., Toronto, New-York, London, 1950), 2nd ed. 
20 See EPAPS Document No. xxx for the optimized geometries used in the calculations of the potential energies for the ground state $\left(\mathrm{S}_{0}\right)$ and the four lowest excited states $\left(\mathrm{S}_{1}\right.$ to $\left.\mathrm{S}_{4}\right)$. This document may be retrieved via the EPAPS homepage (http://www.aip.org/pubservs/epaps.html) or from ftp.aip.org in the directory /epaps/. See the EPAPS homepage for more information.

21 P. M. Anderson and M. R. Wilson, Mol. Phys. 103, 89 (2005). 


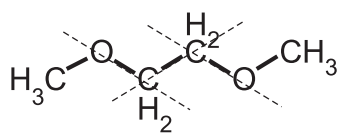

$\mathrm{tt} \mathrm{t}$

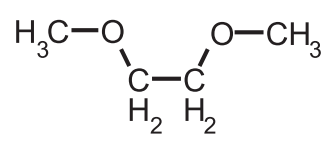

$\operatorname{tg} t$

FIG. 1: Scheme of two rotamers of the 1,2-dimethoxyethane (DXE) molecule. The dashed lines on the $t t t$ rotamer are the axes, which define the trans $(t)$ and gauche $(g)$ conformations. 


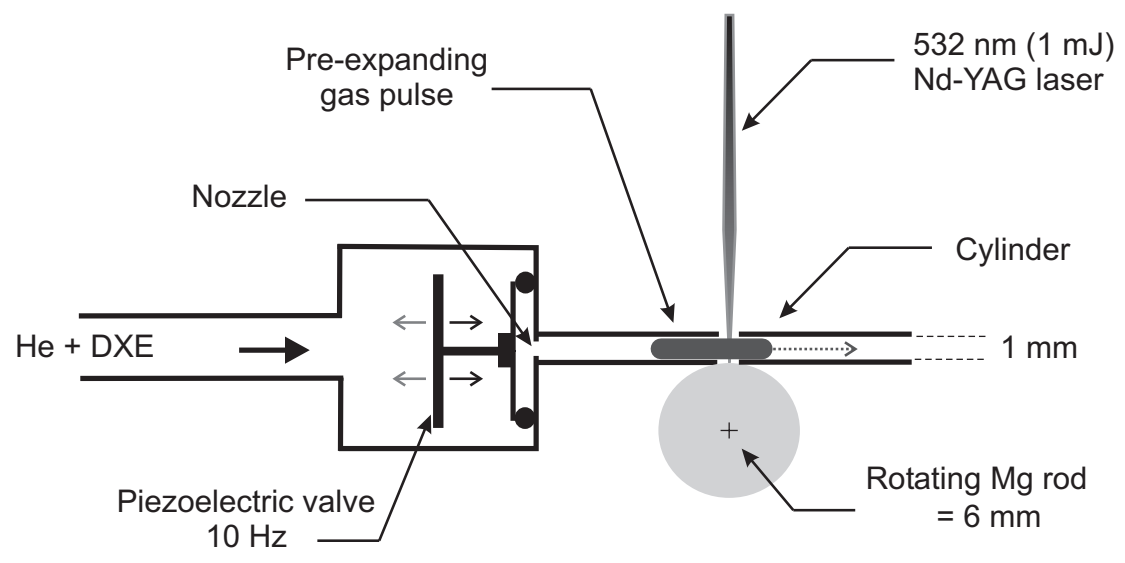

FIG. 2: Outline of the laser ablation-molecular beam experimental setup used to obtain cold coordination complexes. 


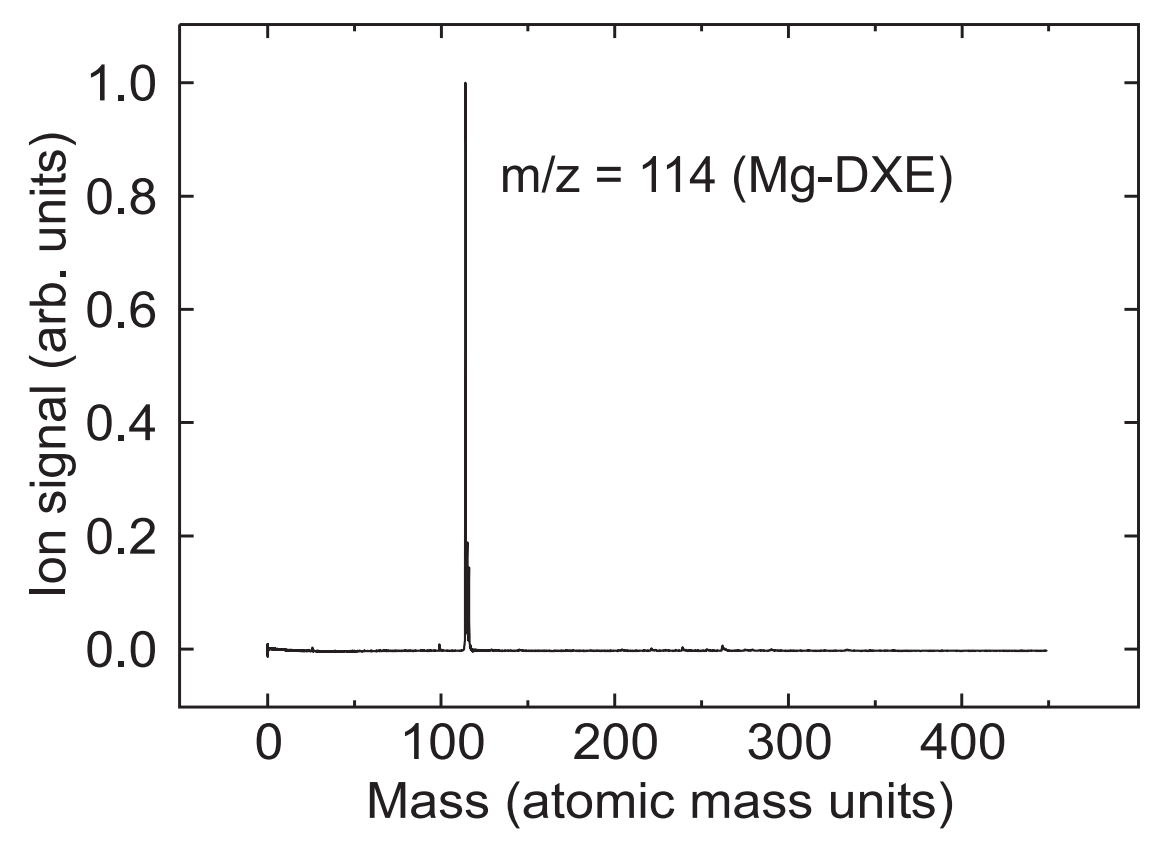

FIG. 3: Mass spectrum observed in a Resonance Two Photon Ionization $(1+1)$ experiment at 345 $\mathrm{nm}$. The expansion conditions are optimized so as to form preferentially the 1:1 Mg-DXE complex as explained in the text. 


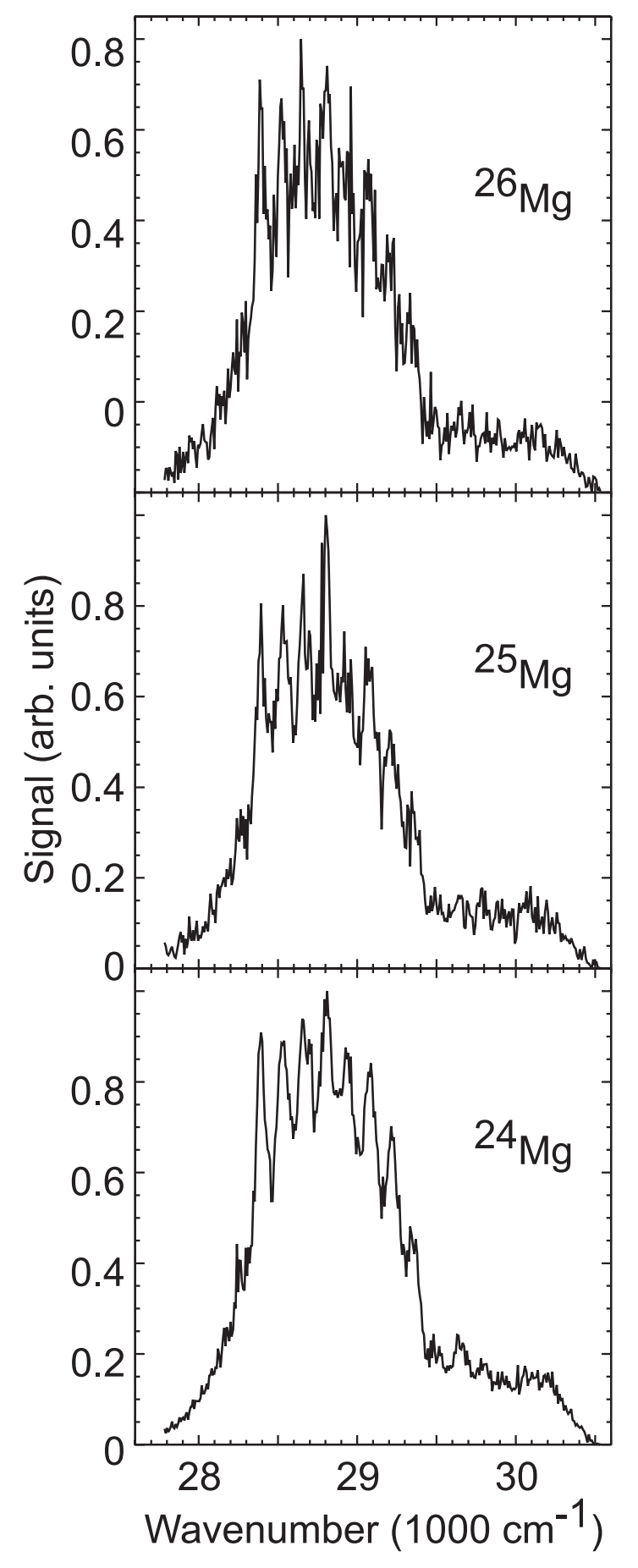

FIG. 4: R2PI spectrum of the 1:1 Mg-DXE complex. The three spectra correspond to the natural isotopes of magnesium, as labeled in the figure. 


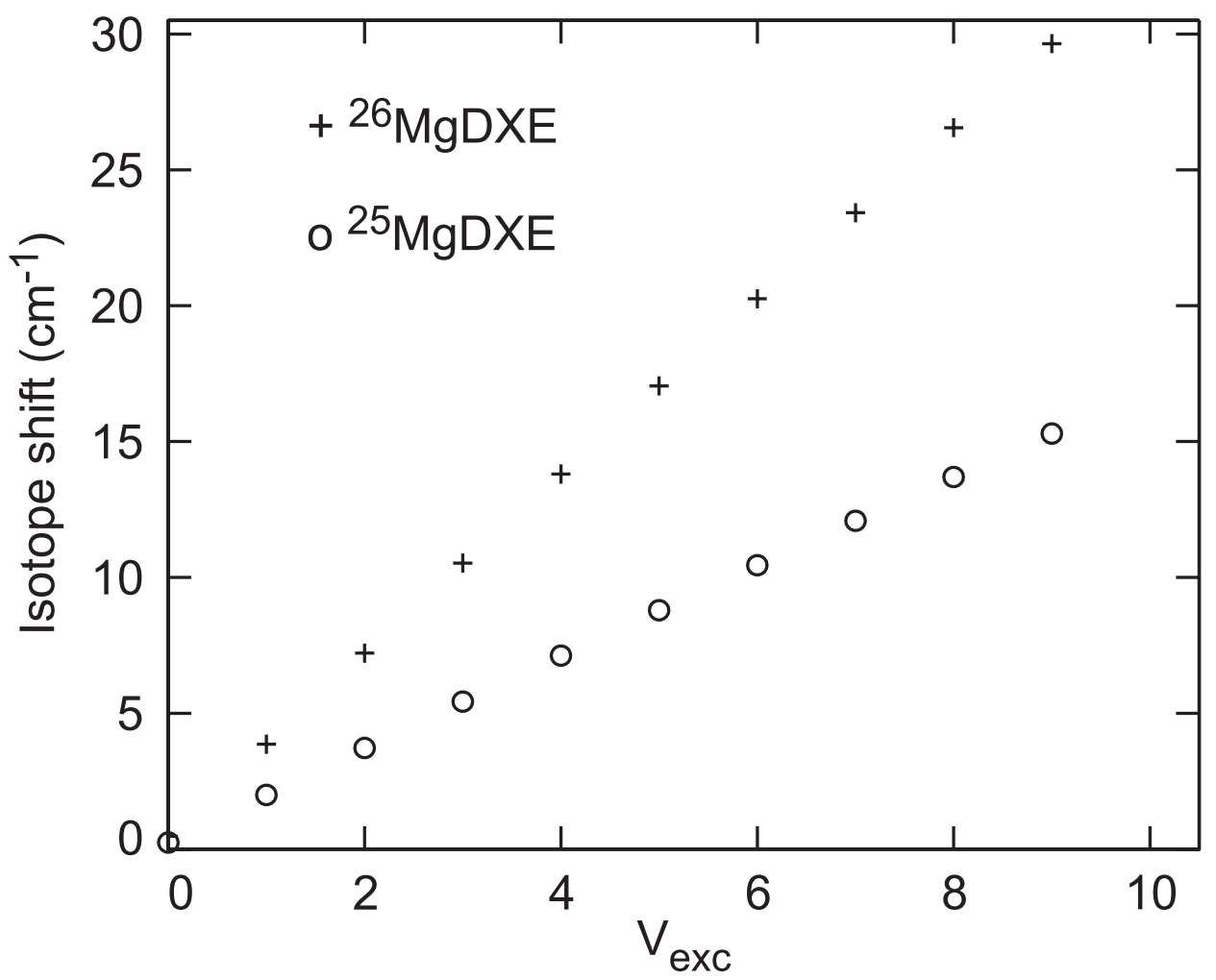

FIG. 5: Simulation of the isotopic shift for the vibrational stretching mode Mg-DXE, assuming a vibrational frequency $\omega_{\mathrm{e}}=110 \mathrm{~cm}^{-1}$ consistent with the separation between the structures observed in Fig. 4. The isotopic shift is relative to the most abundant isotope, ${ }^{24} \mathrm{Mg}-\mathrm{DXE}$. It is given as a function of the vibrational level of the excited state, $\mathrm{v}_{\text {exc }}$, for ${ }^{25} \mathrm{Mg}-\mathrm{DXE}(\mathrm{o})$ and ${ }^{26} \mathrm{Mg}-\mathrm{DXE}(+)$. 


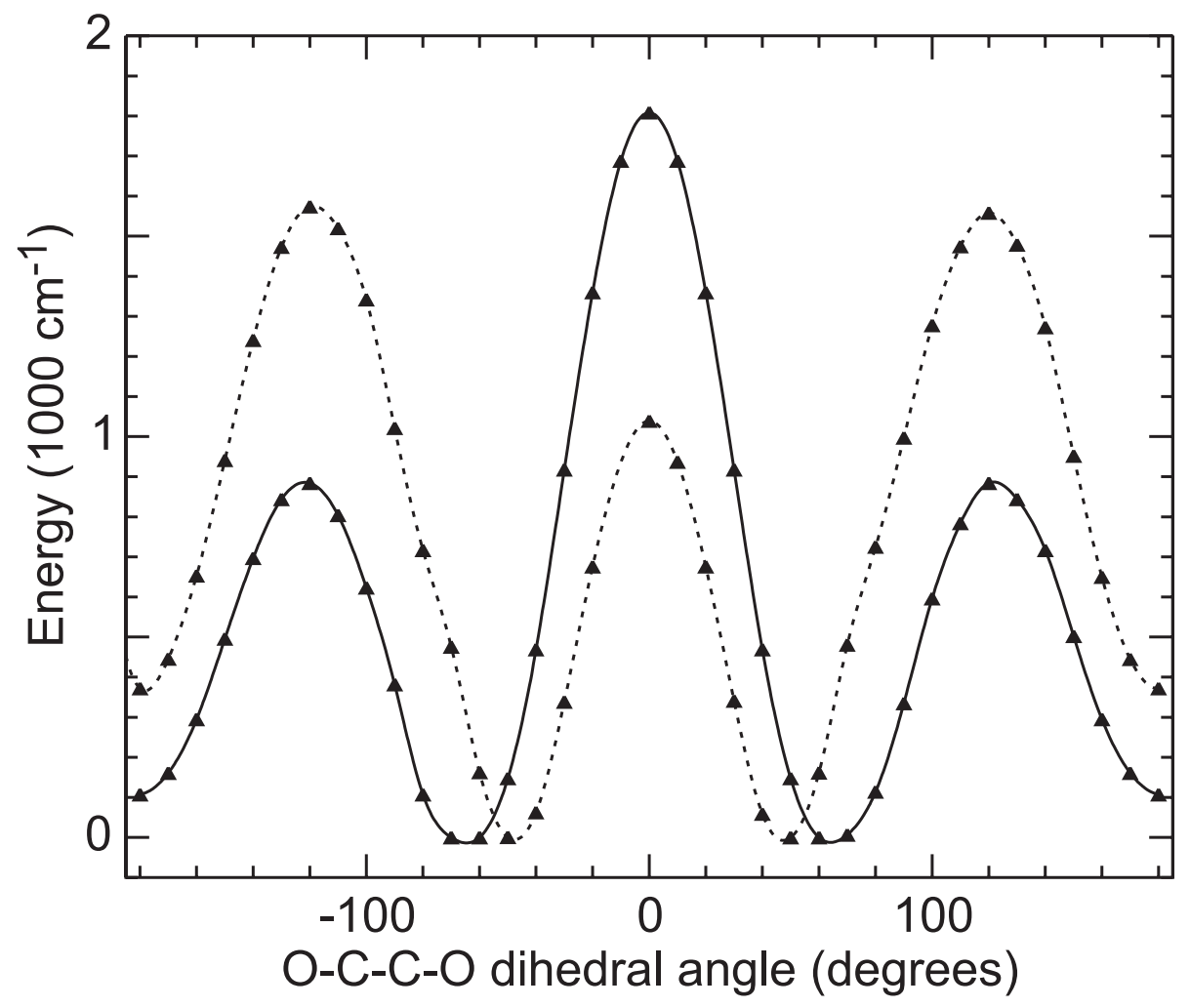

FIG. 6: Ground state potential energy of the Mg-DXE complex as a function of the O-C-C-O dihedral angle. The full and dashed curves are obtained from the DFT/B3LYP/6-311++ $\mathrm{G}^{* *}$ and MCSCF +IC-MRCI calculations, respectively. The curve are spline fits to the calculated points, which are shown as full triangles. The O-C-C-O skeleton of DXE is planar when the O-C-C-O dihedral angle is equal to $0^{\circ}$ and $\pm 180^{\circ}$, having the boat and chair conformations, respectively. $\mathrm{See}^{20}$ for the optimized geometries used in the calculations. 


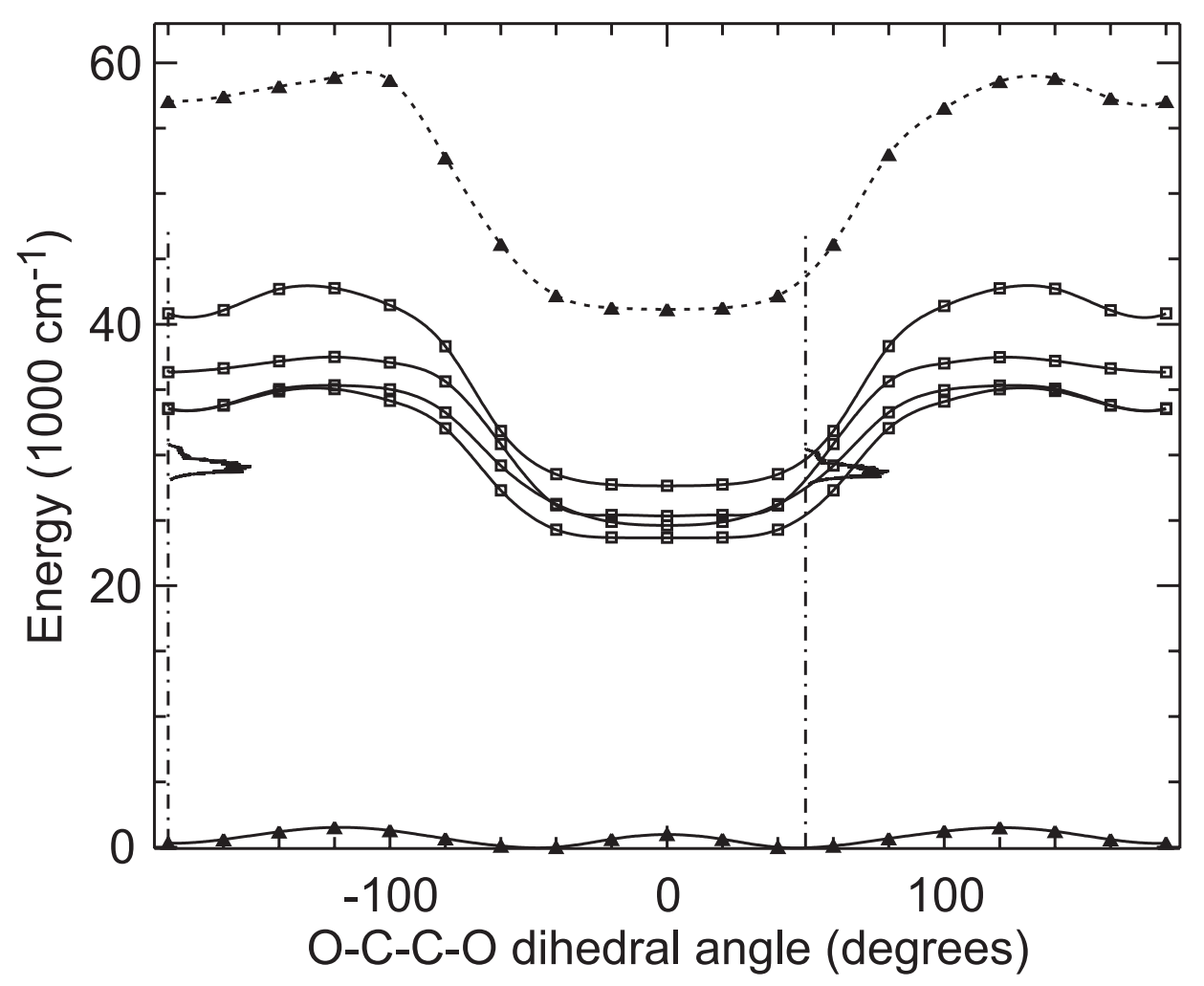

FIG. 7: Potential energies provided by the MCSCF+IC-MRCI calculations for the ground state $\left(\mathrm{S}_{0}\right)$ and the four lowest excited states $\left(\mathrm{S}_{1}\right.$ to $\left.\mathrm{S}_{4}\right)$ of the Mg-DXE complex and for the ground state of the $\mathrm{Mg}^{+}$-DXE ion as a function of the O-C-C-O dihedral angle. The excited and ionic curves represent the vertical excitation and ionization energies from the ground state. The experimental R2PI signal of Fig. 4 is reproduced, assuming a vertical excitation from either the absolute or the secondary minimum of the ground state curve. The dotted-dashed lines are plotted at the absolute and secondary minima of the ground state curve. Their length, $47183 \mathrm{~cm}^{-1}(5.85 \mathrm{eV})$, corresponds to the energy of the photon used to characterize the beam in Sec. III A. See ${ }^{20}$ for the optimized geometries used in the calculations. 

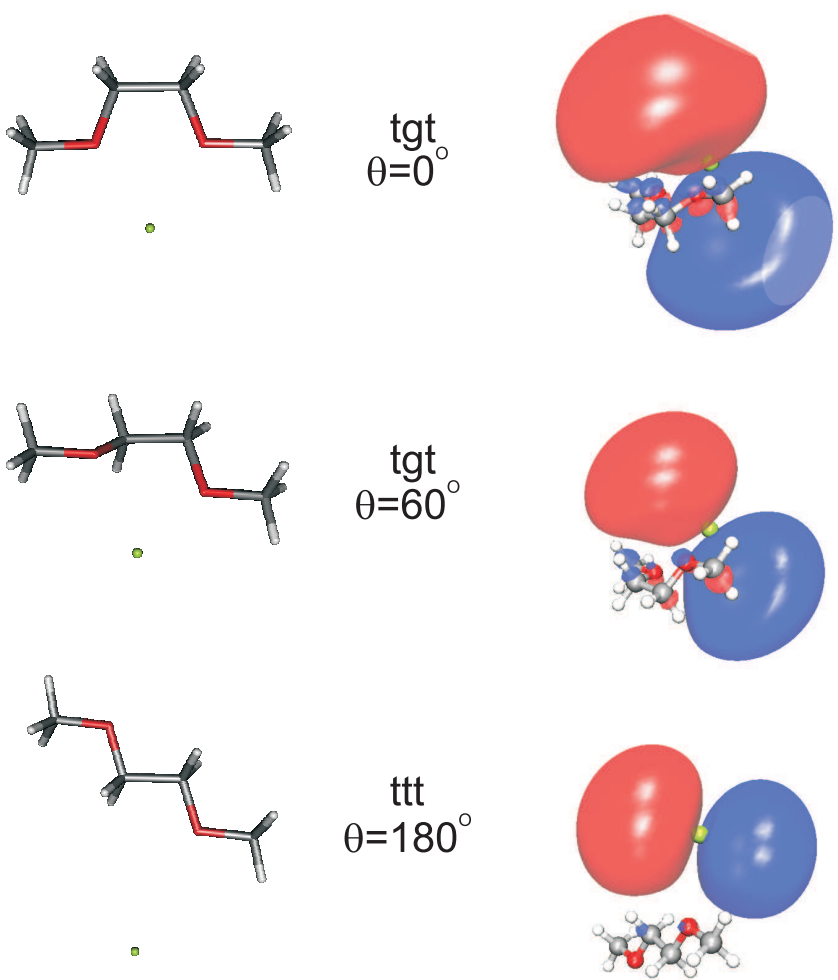

FIG. 8: Output of the Gaussian calculation (left) showing the geometry of the Mg-DXE system for three values of the $\mathrm{O}-\mathrm{C}-\mathrm{C}-\mathrm{O}$ dihedral angle $\theta, 0^{\circ}, 60^{\circ}$ and $180^{\circ}$, from top to bottom, respectively. The $\mathrm{Mg}$ atom is shown in green and the $\mathrm{O}$ atoms in red. The corresponding first excited orbital provided by the state averaged MCSCF step of the MOLPRO calculation is shown on the right side of the figure, together with the Mg-DXE system. 


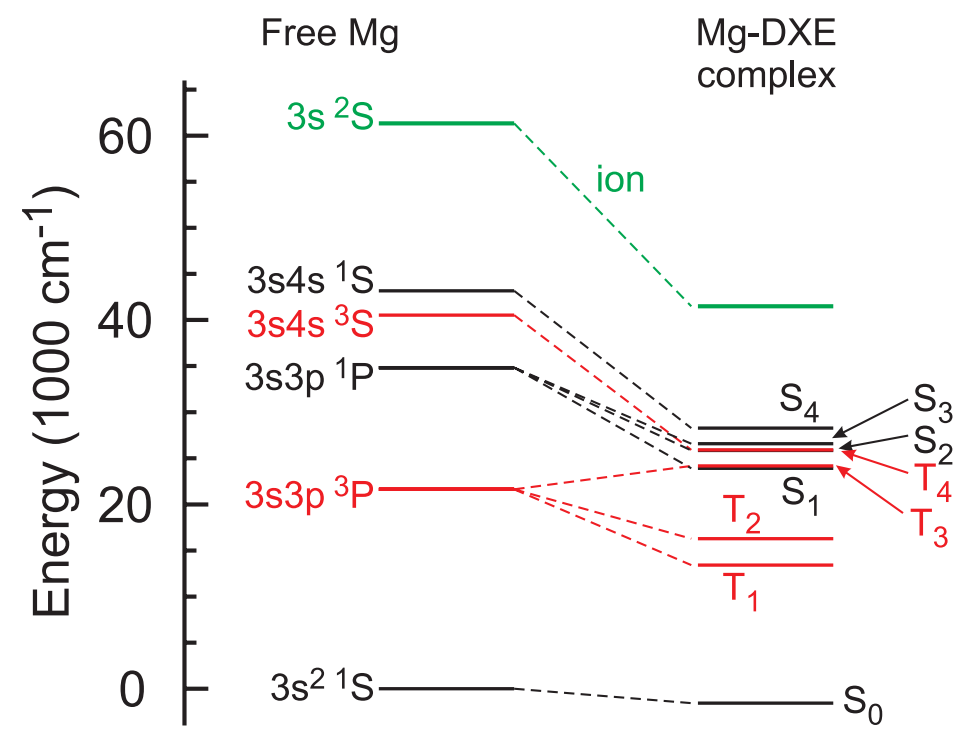

FIG. 9: Correlation diagram between the energy states of free $\mathrm{Mg}$ and those of the $\mathrm{Mg}$-DXE complex at the equilibrium geometry of the ground state complex (O-C-C-O dihedral angle equal to $48^{\circ}$. Singlet and triplet states are in black and red, respectively. The correlation between $\mathrm{Mg}^{+}$ and $\mathrm{Mg}^{+}$-DXE is shown in green. 
TABLE I: Term symbols and ionization energies of Mg atom. The column labeled $\Delta$ is the energy difference between experiment (Exp.) and calculation (Calc.). All energy values are given in $\mathrm{cm}^{-1}$.

\begin{tabular}{|c|c|}
\hline Level & Exp. $^{\mathrm{a}}$ Calc. $^{\mathrm{b}} \Delta$ \\
\hline \multicolumn{2}{|r|}{$\mathrm{Mg}$} \\
\hline $3 \mathrm{~s}^{2}{ }^{1} \mathrm{~S}$ & 0 \\
\hline $3 s 3 p{ }^{3} \mathrm{P}$ & 2189121620271 \\
\hline $3 s 3 p{ }^{1} \mathrm{P}$ & 3505134832219 \\
\hline $3 \mathrm{~s} 4 \mathrm{~s}{ }^{3} \mathrm{~S}$ & 4119740540657 \\
\hline $3 \mathrm{~s} 4 \mathrm{~s}^{1} \mathrm{~S}$ & 4350343162341 \\
\hline & $\mathrm{Mg}^{+}$ \\
\hline $3 \mathrm{~s}^{2}{ }^{2} \mathrm{~S}$ & 6166961330339 \\
\hline${ }^{a}$ Ref. ${ }^{13}$ & \\
\hline $\mathrm{b}$ This $\mathrm{y}$ & work, IC-MRCI cal- \\
\hline
\end{tabular}


TABLE II: Vertical excitation and ionization energies of Mg-DXE. The energies $\left(\mathrm{cm}^{-1}\right)$ are given for each state at 4 geometries of the DXE moiety, each characterized by the dihedral angle $\theta$. All energies are referred to the ground state in each geometry.

\begin{tabular}{|c|c|c|c|c|}
\hline \multicolumn{2}{|c|}{ Level $\theta=0^{\circ}$} & \multicolumn{2}{|c|}{$\theta=48^{\circ} \theta=60^{\circ}$} & \multirow[t]{2}{*}{$\theta=180^{\circ}$} \\
\hline \multicolumn{4}{|c|}{$\mathrm{Mg}-\mathrm{DXE}$} & \\
\hline $\mathrm{S}_{0}$ & 0 & 0 & 0 & 0 \\
\hline $\mathrm{S}_{1}$ & 22685 & 25492 & 27190 & 33202 \\
\hline $\mathrm{S}_{2}$ & 23637 & 27416 & 29077 & 33255 \\
\hline $\mathrm{S}_{3}$ & 24354 & 28151 & 30730 & 36024 \\
\hline $\mathrm{S}_{4}$ & 26665 & 29863 & 31729 & 40501 \\
\hline $\mathrm{T}_{1}$ & 13574 & 14983 & 15994 & 20111 \\
\hline $\mathrm{T}_{2}$ & 16693 & 17858 & 18580 & 20394 \\
\hline $\mathrm{T}_{3}$ & 23180 & 25751 & 25893 & 24021 \\
\hline $\mathrm{T}_{4}$ & 24431 & 27498 & 29930 & 38356 \\
\hline \multicolumn{5}{|c|}{$\mathrm{Mg}^{+}-\mathrm{DXE}$} \\
\hline $\mathrm{D}_{0}$ & 40274 & 43082 & 45474 & 56643 \\
\hline
\end{tabular}

